\title{
The Influence of Emotional Reaction on Help Seeking by Victims of School Bullying
}

\author{
Simon C. Hunter ${ }^{\mathrm{a} *}$ and Mark G. Borg ${ }^{\mathrm{b}}$ \\ ${ }^{\mathrm{a}}$ University of Strathclyde, $U K{ }_{;}{ }^{\mathrm{b}}$ University of Malta, Malta
}

\begin{abstract}
Research has begun to focus on how victims of school bullying cope, but there is still little understanding of why pupils will cope in one particular way and not another. This paper aimed to examine the effects of gender, stage of schooling, frequency of victimisation, and different emotions (anger, vengeance, self-pity, indifference, and helplessness) upon the social support that children report using. Questionnaires were completed by 6,282 Maltese schoolchildren between 9 and 14 years of age. Analyses revealed that specific patterns of emotion and victimisation predict pupil reports of using certain sources of social support. Results are discussed in relation to possible intervention, future research needs, and implications for the theoretical framework used.
\end{abstract}

Being bullied at school is a distressing event (Sharp, 1995) experienced by up to $27 \%$ of children during any given term (Boulton \& Underwood, 1992; Whitney \& Smith, 1993). The effects of bullying upon victims include increased levels of depression and anxiety (Bond, Carlin, Thomas, Rubin, \& Patton, 2001; Craig, 1998; KaltialaHeino, Rimpela, Marttunen, Rimpela, \& Rantanen, 1999; Kumpulianen \& Räsänen, 2000), reduced self-esteem (Karatzias, Power, \& Swanson, 2002; O’Moore \& Kirkham, 2001; Salmivalli, Kaukiainen, Kaistaniemi, \& Lagerspetz, 1999), and heightened suicidal ideation (Kaltiala-Heino et al., 1999; Roland, 2002). This suggests that many victims of bullying are not coping effectively with the distress associated with being bullied, and has prompted a number of researchers to examine the ways in which victims cope (e.g., Borg, 1998; Hunter \& Boyle, 2004; Kochenderfer-Ladd \& Skinner, 2002).

\footnotetext{
*Corresponding author. Department of Psychology, University of Strathclyde, Graham Hills Building, 40 George Street, Glasgow, G1 1QE, UK. Email: simon.hunter@strath.ac.uk
} 
However, less attention has been focused on why victims choose to cope in one way rather than another. This is an important omission from the research literature, as a greater understanding of why pupils cope in one way instead of another could benefit intervention efforts in two ways. First, it may be possible to equip pupils better to carry out certain coping strategies. For example, if children who are very scared in a bullying situation find it difficult to be assertive, it may be necessary first to teach those pupils how to control their fear before giving them assertiveness training (as advocated by, among others, Smith, Shu, \& Madsen, 2001). Second, intervention may benefit from a clearer understanding of what drives pupils to engage in certain strategies. For example, if pupils who ask for help do so because they are experiencing feelings of helplessness and anger, then these may need to be addressed by the teacher (or parent) while the practicalities of stopping the bullying are also attended to.

With this in mind, the focus of the current article is on the extent to which bullied pupils report turning to different sources (parents, other children, teachers) for help and, specifically, on the effects of different emotions upon the use of each of these sources. It is important to examine the extent to which children report their experience of bullying to others, as many anti-bullying programs encourage victims to tell someone so that they can then be helped to resolve the problem (Glover, Gough, Johnson, \& Cartwright, 2000), and trainee teachers report this as the number one coping strategy they would recommend to students (Nicolaides, Toda, \& Smith, 2002). Furthermore, students are encouraged to speak to their parents/guardians (Hunter, Boyle, \& Warden, 2004) and other students (e.g., where peer support systems exist; see Naylor \& Cowie, 1999; Smith \& Sharp, 1994).

When examining the relationship between emotional reactions and telling, transactional models of coping can be useful as they emphasise the importance of emotion in the coping process (Lazarus, 1999). Such models view coping strategy use as determined primarily by situation-based appraisals (i.e., perceptions of the situation, such as perceived control) and emotional reactions. Research by Hunter et al. (2004) supports the supposition that emotions influence coping strategy use among victims of bullying. These researchers examined duration and frequency of bullying, appraisals, experience of negative emotions, and frequency of telling among 305 victims of peer aggression and bullying aged between 9 and 14 years of age. Their measure of negative emotion asked pupils about their experience of nine different emotions (anger, worry, fear, shame, sadness, jealousy, guilt, disappointment, and disgust) during an episode of victimisation. An average of these was then taken to produce a measure of negative emotion. They found that the most important factor in predicting the frequency of telling was gender, with girls more willing to seek out social support than boys. However, as the experience of negative emotion increased, so too did the frequency with which victims sought social support. Stage of schooling, duration/frequency of victimisation, and both threat and control appraisals did not increase the likelihood of reported help seeking behaviour beyond that predicted by gender, negative emotion, and challenge appraisals. Although other research has examined victims' use of social support (e.g., Borg, 1998; Glover 
et al., 2000; Pateraki \& Houndoumadi, 2001; Sharp, 1995), Hunter et al.'s (2004) research appears to be the only published study examining the effect of emotions upon victimised children's reported use of social support.

Outside the bullying/peer victimisation literature, Beaver (1997) examined children's general coping strategies and emotional responses to everyday stressors. She presented children in Grades 1, 3, and 5 with vignettes, and asked them to rate the protagonist's emotions (anger, sadness, or fear) and likely coping strategy. She found that strategy use differed according to the emotions of the story character. Coping strategies were more likely to focus on the self when feeling scared, but were more likely to focus on the environment when feeling angry. Additionally, children were more likely to inhibit actions when faced with fear-arousing situations than when faced with situations involving anger or sadness. Beaver also noted that girls were more likely than boys to use cognitive strategies when angry, yet the opposite pattern was evident in the sadness and fear conditions. Finally, older children used more cognitive coping.

It is thus important that we understand why children and adolescents turn to others for help, as well as who they ask, as such information might help those advising/helping victims to understand better what is expected, or asked, of them. Previous research supports the importance of a link between children's emotions and their coping strategy use. To examine this link, data from a previously published article (Borg, 1998) are re-analysed in this article. Borg (1998) surveyed 6,282 Maltese pupils between 9 and 14 years of age about their reactions to being bullied. Pupils were asked what emotions they experienced after being bullied, and about their behavioural reactions. Although these data were examined for possible gender and school-level (primary school compared to secondary school) differences, no examination of their relationship with each other was conducted (the interested reader is referred to Borg, 1998, for the results on gender and school-level differences).

Given that coping processes are thought to be situation-specific rather than personality traits (Lazarus \& Launier, 1978), the associations between emotions and coping strategies reported by Beaver (1998) in relation to general stressors may not be an accurate guide to how emotions within a bullying context will influence coping strategy use. Borg (1998) asked children about their experience of a different set of emotions to Beaver, and also asked about specific sources of social support (e.g., friend, teacher, parent) rather than support seeking in general.

It is expected here that feelings of helplessness and self-pity will be important predictors of whether children ask adults for help, while feelings of anger and vengeance will be important predictors of whether they ask their friends for help. These predictions are made on the following basis:

- Feelings of anger and vengeance are likely to be associated with a desire to gain revenge on the victim's part, a desire that is more likely to be supported by friends than adults.

- Feelings of helplessness and self-pity are likely to be associated with asking for help from someone in a position to deal independently with the problem, such as an adult. 
In addition, it is expected that frequently bullied pupils will be more likely to seek help from all sources examined, compared to less frequently bullied pupils. This is based on research findings indicating that more frequent bullying leads to more use of social support (Smith et al., 2001) among 10-14-year-old students. Smith, Talamelli, Cowie, Naylor, and Chauhan (2004) also report that talking to someone about it was a strategy used more by frequently bullied pupils between 13 and 16 years of age.

\section{Method}

\section{Participants}

A total of 6,282 Maltese schoolchildren participated in the survey by completing a self-administered questionnaire. Pupils in the primary school sample were in Year 5 and Year 6 (aged $9+$ to $11+$ ), and pupils in the secondary school sample were in Forms 1-4 (aged $11+$ to $14+$ ). Girls made up $50.3 \%$ of the sample.

Further details of the sample are reported in Borg (1998).

\section{The Questionnaire}

The questionnaire was based on those developed by Olweus (1993) and other researchers (e.g., O’Moore \& Hillery, 1989; Whitney \& Smith, 1993). It contained 22 items and was organised into three sections. The first section examined the incidence of, nature of, and reactions to bullying from the victim's point of view. The second section paralleled the first, but from the bully's point of view. The third asked for biographical information. Participants completed the questionnaire in their class groups, and a research assistant (RA) was present at all times. The RA explained the meaning of all terms used, and an appropriate story was presented at the beginning to illustrate what bullying was and to focus the children's attention. Frequency of victimisation was recorded using the same response categories as Olweus (1993): “never", “once or twice", “sometimes", “about once a week", and "several times a week". Participants were asked about their experiences of victimisation over the preceding two terms (i.e., approximately six months); $41.3 \%$ reported that they had not been bullied, $18.4 \%$ reported that they had been bullied once or twice, and $40.3 \%$ reported that they had been bullied sometimes or more often.

Two of the survey questions are of particular relevance here. As noted earlier, pupils were asked what emotions from the following list they experienced after being bullied: angry, vengeful, self-pity, indifferent, and helpless. The RA explained any unfamiliar terms to the children with reference to common experiences. Students could choose all five options if they so desired, although in practice most chose one (57.8\% of students), two (27.4\% of students), or three ( $11.2 \%$ of students) emotional reactions. They were also asked to indicate their behavioural reactions ("did nothing", "told my best friend", "sought a friend's help", "sought my friends' help", "sought a teacher's/ teachers' help", "sought the headteacher's help", "sought 
parental help", and "other"). Most students chose one (56.4\% of students), two ( $18.9 \%$ of students), or three $(8.9 \%$ of students) coping strategies.

\section{Procedure}

Participants completed questionnaires during the first two to three weeks of the third term of the academic year. By way of introduction, and in order to ensure that pupils understood what was meant by "bullying", the negative nature and effects of bullying were highlighted by means of a short story adapted to the age of the respondents. Essentially, the story communicated to the pupils that bullying is an undesirable and unacceptable form of behaviour, that victims should be supported and protected, and that perpetrators should be reported to the school administration, if anything for their own sake. Care was also taken to pass on the message that the problem is not the bully but bullying, and that more often than not bullies may be in need of as much help as their victims. Each session took about 30 minutes to complete.

A small number of questionnaires were eliminated from further analysis either because pupils were observed copying from their neighbors or because they completed the questionnaire haphazardly.

\section{Statistical Analyses}

Data were analysed using SPSS 10. Logistic regression was carried out to examine the influence of each emotion (angry, vengeful, self-pity, indifferent, helpless) upon each coping strategy. Gender, stage of schooling (primary vs. secondary), and frequency of bullying (once or twice vs. sometimes or more often) were entered as a first step in the logistic regression in order to control for their influence. Emotions were included as predictors at the second step. Seven logistic regressions were calculated in total (one for each coping strategy). To reduce the possibility of making Type II errors, the significance level was amended, using a Bonferroni correction, from .05 to .007 (i.e., .05/7). It is notable that $8.4 \%$ of pupils reported using none of the strategies listed, despite the inclusion of the options "did nothing" and "other" to capture all possible responses.

\section{Results}

Descriptive statistics regarding gender and school-level differences in each of the emotions and each of the coping strategies are reported by Borg (1998) and hence are not repeated here. However, Table 1 (primary school pupils) and Table 2 (secondary school pupils) show the percentages of pupils who reported using particular strategies, shown according to gender, frequency of bullying, and whether pupils experienced or did not experience each emotion.

The results from the logistic regression analyses are summarised in Table 3. Gender and school stage results were the same as reported in the previous analysis of these data (Borg, 1998). Gender was a significant predictor of each strategy 


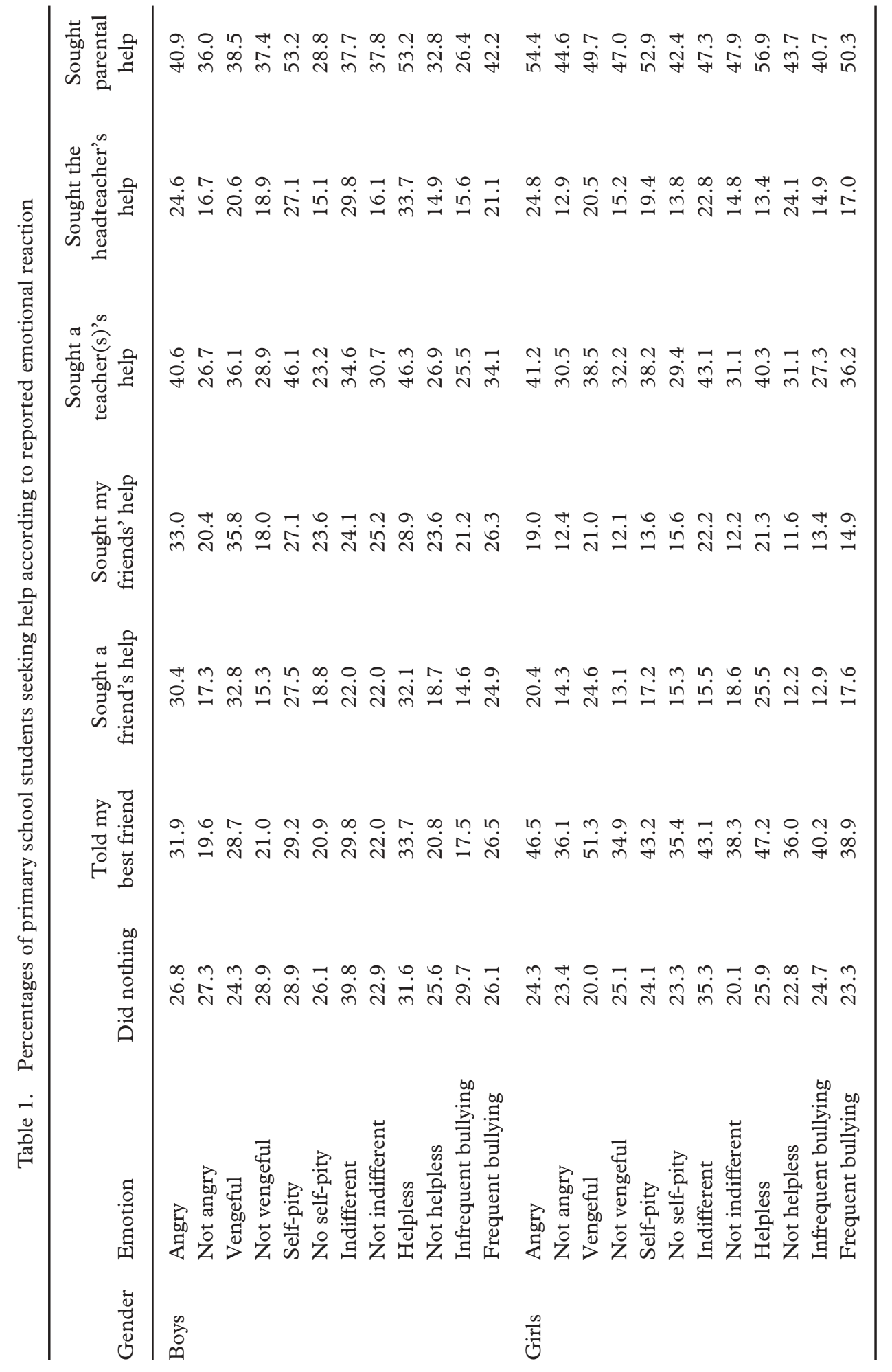




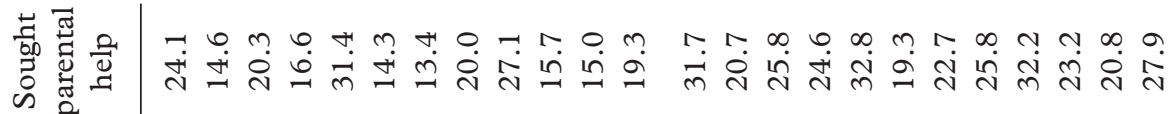

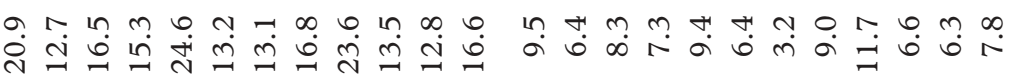

亗

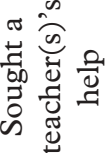

苻

要

萑售

嵵

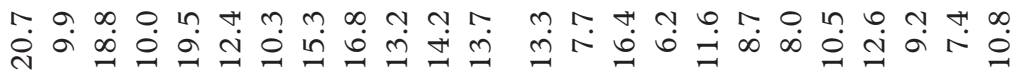

サִ مُ

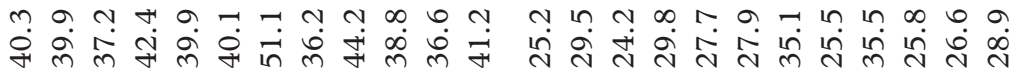




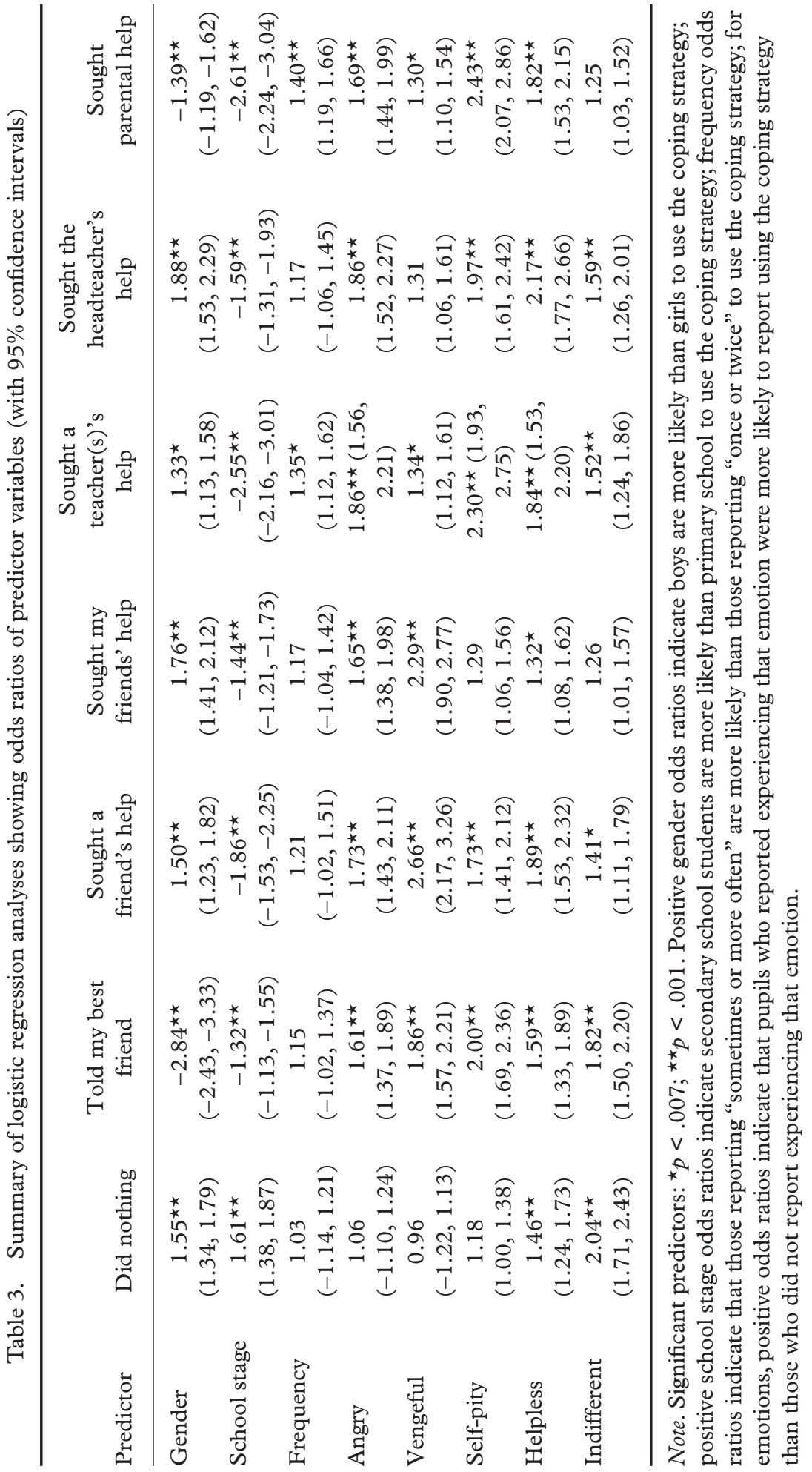


examined. Boys were more likely than girls to use the strategies "do nothing about it", "sought a friend's help", "sought my friends' help", "sought a teacher's help", and "sought the headteacher's help". Girls were more likely than boys to use the strategies "told my best friend" and "sought parental help".

There were also differences according to whether pupils were in primary school or secondary school. Those in primary school were more likely to ask for help from all sources included in the survey, while secondary school pupils were 1.6 times more likely to do nothing about it.

Pupils who reported feeling angry were more likely to report asking for help (from all sources examined). However, feelings of anger did not influence whether or not pupils reported that they would do nothing about it. Pupils who reported feeling vengeful were more likely to use all the coping strategies examined, except for doing nothing about it and seeking a teacher's help. Feeling vengeful did not influence the use of these last two strategies. Self-pity predicted greater use of all strategies except doing nothing about it and seeking friends' help. These latter strategies were not influenced by feelings of self-pity. Feeling indifferent predicted more use of each strategy, except seeking friends' help and seeking parental help. Neither of these last two strategies was influenced by whether pupils felt indifferent. Pupils who reported feeling helpless were more likely to use each of the strategies examined.

Frequency of bullying was a significant predictor of the use of two strategies: more frequently bullied pupils reported greater use of seeking a teacher's help and seeking parental help.

Table 3 includes the $95 \%$ confidence intervals (CI) for predictor odds ratios. Inclusion of the CIs allowed comparison of predictors for each strategy (i.e., within columns) on the basis that non-overlapping CIs differ significantly from one another. For example, for the strategy "told my best friend", the CIs for gender and angry do not overlap, indicating that gender is a significantly stronger predictor of this strategy than anger, although both are significant predictors in their own right. Similarly, for the same coping strategy, the predictors of angry and vengeful are both significant, but since their CIs overlap it cannot be inferred that one is a significantly stronger predictor than the other (despite odds ratios of 1.86 for vengeful and 1.61 for angry).

The significant predictors of each strategy were compared. For "did nothing", there were no significant differences in predictor strengths (i.e., odds ratios). For "told my best friend", gender was the strongest predictor, and self-pity and vengeful were also significantly stronger predictors than school stage. For "sought a friend's help", vengeful was a significantly stronger predictor than gender, angry, self-pity, or indifferent, but not school-stage or helpless. For "sought my friends' help", vengeful was significantly stronger than school-stage and helpless. For "sought a teacher(s)'s help", both self-pity and school stage were significantly stronger predictors than gender, frequency of bullying, vengeful, or indifferent. There were no significant differences between the significant predictors of "sought the headteacher's help". Finally, for "sought parental help", school stage was a significantly stronger predictor than gender, frequency of bullying, angry, vengeful, or helpless, but not self-pity. 
Self-pity was significantly stronger than gender, frequency of bullying, angry, or vengeful but not helpless.

\section{Discussion}

Gender and schooling level differences in pupils' use of each strategy were discussed by Borg (1998) and so are not discussed further here. In the current article, interesting relationships were revealed between emotions and the degree to which school pupils turn to others for help, although with few exceptions our hypotheses were not confirmed.

It was hypothesised that feelings of anger and vengeance would predict help seeking amongst friends more than amongst adults. However, the results did not support this hypothesis with regards to anger, as anger predicted the extent to which help was sought from both peers and adults. Lazarus (1999, p. 217, italics in original) defines anger as "a demeaning offence against me and mine. Anger depends heavily on the goal of preserving or enhancing self- or social-esteem"; he goes on to note that anger is associated with the assignment of blame for an offence. Hence, anger may be entwined with blaming an aggressor, and children may seek help as a way of dealing with a loss of esteem where they clearly perceive blame to lie with another. Although it is tempting to assume that all victims would blame bullies, this is not the case (Graham \& Juvonen, 1998; Owens, Slee, \& Shute, 2000; Smith \& Talamelli, 2001), and future research may seek to clarify whether anger, blame assignment, and perceived loss of esteem are indeed linked.

There was a similar pattern of results for vengeance, although this did not predict the extent to which students reported seeking headteacher help. It may be important to impress upon pupils, teachers, and parents that students are more likely to ask for help when they are feeling vengeful, so that they can be helped to deal with their feelings in a non-aggressive way. One way of doing this is to help students manage their response to bullying by being assertive rather than aggressive. Being assertive includes using behaviours such as responding in a calm, confident tone while maintaining eye contact (Smith \& Sharp, 1994), where expression of one's needs maintains respect for other people's needs and rights (Murgatroyd, 1985).

When we consider the results relating to feelings of vengeance, it seems even more important to highlight assertive alternatives to pupils. There may exist a qualitative difference in the feelings of revenge experienced by those pupils getting help from friends and those getting help from adults. From the results, it was clear that pupils feeling vengeful were more than twice as likely to get help from their friends than pupils who did not feel like this. In contrast, they were only 1.3 times more likely to get help from an adult. Thus, it may be the case that pupils want help from their friends to respond in kind to the bully (i.e., being aggressive toward the bully) but that they ask for help from adults in order to get the bully into trouble. Both these possibilities have some support in the literature: Hunter and Boyle (2004) reported that, for $5 \%$ of victims, the main negative outcome they expected as a result of being bullied was that they themselves would become bullies. This may 
take the form of being aggressive by enlisting friends' help, or by getting the bully into trouble.

However, this does not explain why feelings of vengeance do not also predict the likelihood of victims telling a headteacher. It may be that pupils only go to a headteacher once other avenues have been exhausted, and that by the time this point is reached feelings of vengeance are less important than simply getting the problem dealt with effectively. Research designed to examine such emotions in more detail would help to clarify whether this, or some other explanation, is accurate.

Our second hypothesis was that feelings of helplessness and self-pity would be more likely to predict asking for help from adults rather than peers. Results did not support this hypothesis. Feelings of helplessness predicted pupils' use of all types of social support, while feelings of self-pity predicted seeking help from all sources examined except for a group of friends. Feelings of self-pity, as noted by Borg (1998), are emotions that are inward looking and directed toward inactivity. Selfpity may predict use of social support because it represents feelings of inadequacy in relation to the self; as such, pupils may turn to a friend, teacher, or parent in order to have such feelings challenged, or to discuss these emotions. This may explain why victims do not turn to a group of friends when feeling this way, as such feelings are likely to be highly personal and as such more easily disclosed to a close friend or trusted adult.

It appears that feelings of helplessness lead pupils to seek out help from both adults and peers. While such a finding is to some degree tautological, for those involved in designing intervention programs it serves to highlight the importance of taking such feelings into consideration. For example, the assertiveness training outlined earlier in this discussion may be inappropriate when pupils perceive themselves to be helpless, and at the very least such feelings of helplessness may need to be addressed as part of such programs.

It is also notable that feeling helpless also predicted pupils' doing nothing. The feelings of helplessness reported by pupils when they do nothing may be different from those reported by those who turn to someone else for support or help. For example, it may be the case that some pupils feel that nothing can be done to alleviate their situation, resulting in them doing nothing about it. Other pupils may, in contrast, feel that they alone cannot do anything about the situation, but that something could be done if they enlisted the help of a friend, parent, or teacher. Future research should clarify whether such differences do indeed exist between pupils who seek help and those who do not. In particular, clarification of what support pupils expect when they feel helpless could provide useful information. For example, it may allow targeting of messages towards pupils who do not seek help, in order to try and encourage more pupils to come forward.

The coping response of doing nothing about it was different from the other coping responses examined; it was the only one that was not specifically a social support coping strategy. Doing nothing about it was not influenced by the emotions of anger, vengeance, or self-pity, whereas all six of the social support strategies were predicted by at least two of these three emotions. However, bullied pupils were more likely to 
say they did nothing when they reported feeling indifferent or helpless. This pattern of results suggests that pupils who do nothing either do not really care about the situation in which they find themselves (they are indifferent) or they are simply feeling helpless.

Finally, there were the reports of pupils feeling indifferent. This predicted use of support from individual friends and teachers, but not from groups of friends or from parents. This conflicts with Borg's (1998) interpretation that pupils who feel indifferent are simply accepting the situation as one that should be passively accepted. Instead it suggests that pupils who report feeling indifferent to being bullied still seek out someone to speak to and, in fact, even go as far as to tell teachers. This may indicate that, far from feeling nonchalant about the whole experience, pupils professing to be indifferent are projecting such an attitude as a coping mechanism. In reality, such pupils may be just as much in need of support as pupils who are willing to admit to being upset by bullying.

Aside from the effects of emotional reaction, we also hypothesised that more frequently bullied pupils would use more social support than less frequently bullied pupils. This hypothesis was only partially supported; more frequently bullied pupils only reported more use of teachers' (though not headteachers') and parental help. This may indicate that it is only when victimisation reaches a certain frequency that pupils perceive it to be serious enough to report to teachers and parents. The fact that the same did not hold true for telling headteachers may be related to the fact that children were generally less likely to seek help from headteachers than other adults. This finding indicates that teachers and guardians need to be aware that bullying is likely to be a fairly frequent occurrence in pupils' lives before they the report it to adults, and hence should be taken seriously.

This finding may reflect children's perception that more frequent bullying requires adult intervention, perhaps because it is perceived as more serious. Conversely, it may be that children who tell adults about bullying are bullied more often, perhaps as a consequence of being pejoratively labeled a "tell-tale". 1

Interestingly, frequency of bullying was not related to how often pupils told peers about bullying. Frequent victimisation provides frequent opportunities to report the problem, and may not reflect an association with the actual severity of the problem, a confound which has been highlighted by other researchers examining coping strategy use in relation to frequency and/or duration of bullying (Smith et al., 2001). The current results suggest that it is not always the case that more frequent bullying leads to more use of coping strategies; rather, it increases the use of certain strategies, reducing the concern that more frequent bullying is always associated with more use of all strategies.

In addition to the individual points discussed above, it is important to note the broader issue here-that emotions are important predictors of coping strategy use. This is consistent with the theoretical standpoint of Lazarus (1999) and emphasises that researchers seeking to understand why pupils cope with bullying in certain ways would benefit by including measures of emotion. However, as above, a more detailed examination of emotional reactions may be required so that the purpose of 
coping strategies is more clearly understood. For example, it may be necessary to clarify what pupils mean when they report feeling helpless: do they mean that they view the situation as one which is essentially beyond any control, or do they view it as one which is beyond their control? Clarification of such issues can inform professionals working directly with children and adolescents about what students expect when they ask for help, as well as why they do not ask for help.

The main limitation of the present study, from a transactional coping perspective, was the lack of any data on student appraisals (for example, perceived control). These have been shown to be important predictors of coping strategy choice for bullied pupils (Hunter \& Boyle, 2004) and may interact in significant ways with emotions. It is therefore recommended that future research not only examine emotions in more detail, but also include measures of appraisal.

\section{Note}

1. We would like to thank an anonymous reviewer for highlighting this point.

\section{References}

Beaver, B. R. (1997). The role of emotion in children's selection of strategies for coping with daily stress. Merrill-Palmer Quarterly fournal of Developmental Psychology, 43, 129-146.

Bond, L., Carlin, J. B., Thomas, L., Rubin, K., \& Patton, G. (2001). Does bullying cause emotional problems? A prospective study of young teenagers. British Medical fournal, 323, 480-484.

Borg, M. G. (1998). The emotional reactions of school bullies and their victims. Educational Psychology, 18, 433-444.

Boulton, M. J., \& Underwood, K. (1992). Bully/victim problems among middle school children. British fournal of Educational Psychology, 62, 73-87.

Craig, W. M. (1998). The relationship among bullying, victimisation, depression, anxiety, and aggression in elementary school children. Personality and Individual Differences, 24, 123-130.

Glover, D., Gough, G., Johnson, M., \& Cartwright, N. (2000). Bullying in 25 secondary schools: Incidence, impact and intervention. Educational Research, 42, 141-156.

Graham, S., \& Juvonen, J. (1998). Self-blame and peer victimisation in middle school: An attributional analysis. Developmental Psychology, 34, 587-599.

Hunter, S. C., \& Boyle, J. M. E. (2004). Appraisal and coping strategy use in victims of school bullying. British fournal of Educational Psychology, 74, 83-107.

Hunter, S. C., Boyle, J. M. E., \& Warden, D. (2004). Help seeking amongst child and adolescent victims of peer-aggression and bullying: The influence of school-stage, gender, victimisation, appraisal, and emotion. British fournal of Educational Psychology, 74, 375-390.

Kaltiala-Heino, R., Rimpela, M., Marttunen, M., Rimpela, A., \& Rantanen, P. (1999). Bullying, depression, and suicidal ideation in Finnish adolescents: School survey. British Medical fournal, 319, 348-351.

Karatzias, A., Power, K. G., \& Swanson, V. (2002). Bullying and victimisation in Scottish secondary schools: Same or separate entities? Aggressive Behavior, 28, 45-61.

Kochenderfer-Ladd, B. J., \& Skinner, K. (2002). Children's coping strategies: Moderators of the effects of peer victimization? Developmental Psychology, 38, 267-278.

Kumpulianen, K., \& Räsänen, E. (2000). Children involved in bullying at elementary school age: Their psychiatric symptoms and deviance in adolescence. An epidemiological study. Child Abuse and Neglect, 24, 1567-1577. 
Lazarus, R. S. (1999). Stress and emotion: A new synthesis. London: Springer.

Lazarus, R. S., \& Launier, R. (1978). Stress-related transactions between person and environment. In L. A. Pervin \& M. Lewis (Eds.), Perspectives in interactional psychology (pp. 287-327). London: Plenum Press.

Murgatroyd, S. (1985). Counselling and helping. London: BPS/ Routledge.

Naylor, P., \& Cowie, H. (1999). The effectiveness of peer support systems in challenging school bullying: The perspectives and experiences of teachers and pupils. Fournal of Adolescence, 22, 467-479.

Nicolaides, S., Toda, Y., \& Smith, P. K. (2002). Knowledge and attitudes about school bullying in trainee teachers. British fournal of Educational Psychology, 72, 105-118.

Olweus, D. (1993). Bullying at school: What we know and what we can do. Oxford, UK: Blackwell.

O'Moore, A. M., \& Hillery, B. (1989). Bullying in Dublin schools. Irish fournal of Psychology, 10, 426-441.

O'Moore, M., \& Kirkham, C. (2001). Self-esteem and its relationship to bullying behaviour. Aggressive Behavior, 27, 269-283.

Owens, L., Slee, P., \& Shute, R. (2000). 'It hurts a hell of a lot...' The effects of indirect aggression on teenage girls. School Psychology International, 21, 359-376.

Pateraki, L., \& Houndoumadi, A. (2001). Bullying among primary school children in Athens, Greece. Educational Psychology, 21, 169-177.

Roland, E. (2002). Bullying, depressive symptoms and suicidal thoughts. Educational Research, 44, $55-67$.

Salmivalli, C., Kaukiainen, A., Kaistaniemi, L., \& Lagerspetz, K. M. J. (1999). Self-evaluated selfesteem, peer-evaluated self-esteem and defensive egotism as predictors of adolescents' participation in bullying situations. Personality and Social Psychology Bulletin, 25, 1268-1278.

Sharp, S. (1995). How much does bullying hurt? The effects of bullying on the personal wellbeing and educational progress of secondary aged students. Educational and Child Psychology, 12, 81-88.

Smith, P. K., \& Sharp, S. (1994). School bullying: Insights and perspectives. London: Routledge.

Smith, P. K., Shu, S., \& Madsen, K. (2001). Characteristics of victims of school bullying: Developmental changes in coping strategies and skills. In J. Juvonen \& S. Graham (Eds.), Peer harassment in school: The plight of the vulnerable and victimised (pp. 332-351). London: Guilford Press.

Smith, P. K., \& Talamelli, L. (2001, March). How pupils cope with bullying: A longitudinal study of successful and unsuccessful outcomes. Paper presented to the British Psychological Society Centenary Annual Conference, Glasgow, UK.

Smith, P. K., Talamelli, L., Cowie, H., Naylor, P., \& Chauhan, P. (2004). Profiles of non-victims, escaped victims, continuing victims and new victims of school bullying. British fournal of Educational Psychology, 74, 565-582.

Whitney, I., \& Smith, P. K. (1993). A survey of the nature and extent of bullying in junior/middle and secondary schools. Educational Research, 35, 3-25. 
Copyright of Educational Psychology is the property of Routledge and its content may not be copied or emailed to multiple sites or posted to a listserv without the copyright holder's express written permission. However, users may print, download, or email articles for individual use. 